\title{
Uma experiência de formação de professor@s de áreas quilombolas por meio da Pret@gogia
}

\section{An experience of teacher education through areas quilombolas Pret@gogia}

\author{
Geranilde Costa e SILVA* \\ NACE/UFC/UFCG
}

Sandra Haydée PETIT**

UFC

Resumo: Expomos uma experiência de formação de professores/as de áreas Quilombolas do semi-árido cearense por meio do I Curso de Pós-graduação Lato Sensu em História e Cultura Africanas e dos Afrodescendentes. Para desenvolver esse curso criamos e aplicamos a Pret@gogia, um referencial teórico-metodológico fincado nos princípios da cosmovisão de base africana e afro-brasileira. Iniciativa do Núcleo das Africanidades Cearenses - NACE -, órgão ligado à Faculdade de Educação da UFC, o curso foi financiado pelo Ministério da Educação através da Secretaria de Educação Continuada, Alfabetização e Diversidade - MEC/SECAD -, atendendo ao Edital de 03/07/2009, com o intuito de desenvolver formação continuada e produção de material didático para as comunidades remanescentes de quilombos. Na prática, essa formação vem significar mais um esforço no sentido de cumprir a Lei de Diretrizes e Bases da Educação por meio da Lei $N^{\circ}$. 10.639/03, que determina o ensino da História e Cultura Africanas e Afro-brasileiras na educação básica.

Palavras-chave: Cosmovisão Africana e Afrobrasileira. Pret@gogia. Currículo. Quilombo. Formação de Professores/as.

\begin{abstract}
We present an experience of teacher training / Quilombolas areas of the semiarid Ceará through I Course Postgraduate Sensu Lato in African History and Culture and People of African Descent. To develop this way we create and apply pedagogy @ Pret a theoretical-methodological stuck on the principles of basic worldview African and Afro-Brazilian. Initiative at the Center of the Ceará Africanidades - NACE, a body linked to the Faculty of Education at the UFC, the course was funded by the Ministry of Education through the Department of Continuing Education, Literacy and Diversity - MEC / SECAD given the Notice 03/07/2009 , in order to develop continuing education and production of educational materials for communities quilombo. In practice, this means more training is an effort to fulfill the Law of Directives and Bases of Education through Law $\mathrm{N}^{\circ} .10 .639 / 03$, which determines the teaching of History and Culture African and Afro-Brazilian basic education.
\end{abstract}

Keywords: African and Afro-Brazilian Worldview. Pret@gogia. Curriculum. Quilombo. Teacher training.
* Doutora em Educação. geranildecostaesilvas0@ gmail.com

** Doutora em Educação.negapetit@ gmail.com 


\section{Breve contextualização}

Apresentamos aqui um dos trabalhos mais profícuos do nosso NEAB (Núcleo de Estudos Afro-Brasileiros), o NACE ou Núcleo de Africanidades Cearenses, com vínculo institucional na Faculdade de Educação da Universidade Federal do Ceará-UFC. O NACE tem por objetivo promover a investigação, discussão e divulgação de conhecimentos sobre as culturas afro-brasileiras e africanas prioritariamente pela pesquisa e extensão universitárias, buscando dar maior visibilidade às intervenções e produções acadêmicas, culturais e políticas referentes aos segmentos afrodescendentes.

Outros objetivos do NACE são: a) subsidiar as Universidades públicas do Ceará (sobretudo a Universidade Federal do Ceará) no debate e nas iniciativas de implementação de ações afirmativas voltadas para a inclusão de negros/as nos sistemas de ensino, bem como nas dimensões curriculares daí decorrentes - formação para pedagogos/as e alunos/as das licenciaturas dentro da perspectiva da Lei N. 10.639/03, das cotas, políticas de permanência e apoio a grupos de pesquisa e extensão; b) divulgar a cosmovisão africana em cursos e projetos de extensão da Universidade, numa perspectiva curricular interdisciplinar e intercultural, nos sistemas de ensino e instituições afins e em espaços comunitários (quilombos, periferias etc.).

Expomos uma experiência de formação de professores/as de áreas Quilombolas do semi-árido cearense desenvolvida pelo NACE durante o I Curso de Pós-graduação Lato Sensu em História e Cultura Africanas e dos Afrodescendentes. Iniciativa do Núcleo das Africanidades Cearenses, o curso foi financiado pelo Ministério da Educação (MEC) através da Secretaria de Educação Continuada, Alfabetização e Diversidade - MEC/ SECAD -, atendendo ao Edital de 03/07/2009. O seu intuito era realizar formação continuada e produção de material didático para as comunidades remanescentes de quilombos. Na prática, essa formação vem significar mais um esforço de cumprimento da Lei de Diretrizes e Bases da Educação por meio da Lei Nº 10.639/03, que determina o ensino da História e Cultura Africanas e Afro-brasileiras na educação básica.

Esse curso de Especialização foi desenvolvido nos Centros de Cultura Negra dos Quilombos Minador e Bom Sucesso, áreas pertencentes ao município cearense de Novo Oriente, distante $400 \mathrm{~km}$ da capital Cearense. Como participantes, tivemos docentes e alguns membros dessas comunidades quilombolas que manifestaram interesse em estudar a referida temática em questão e/ou por se apresentarem como afrodescendentes, como foi o caso de um dos líderes do movimento quilombola do Minador. Contamos também com docentes e técnicos da Secretaria de Educação dos municípios de Pacajus e de Caucaia. Ainda estiveram conosco um grupo de educadores/as do Projeto Mova Brasil (Projeto de Alfabetização de Jovens 
e Adultos financiado pela Petrobrás, executado em Caucaia) O grupo recebeu ainda docentes de Fortaleza e de alguns membros de Terreiros de Umbanda e Candomblé que se interessaram em estudar a temática do curso.

A história no Ceará inicia-se com o registro de populações de quilombos vindas do estado de Pernambuco. Na atualidade, são citadas mais de 60 comunidades rurais afrodescendentes classificáveis como remanescentes de quilombos nas três regiões geográficas do Litoral, Sertão e Serra. A maioria dessas comunidades luta contra a cultura da invisibilidade e negação da existência de negros no estado. Apresentamos a seguir as comunidades quilombolas envolvidas nessa formação:

1. Quilombo do Cumbe: Situado no município de Aracati, distante 6 km do centro urbano. Tem boas estradas durante o ano todo. Sua comunidade possui cerca de dois mil moradores numa área de alagados, mangues e desembocadura de rio para o mar. Trata-se de uma população citada há mais de 100 anos na história local e que, no passado, produziu cana-deaçúcar e produtos de olaria.

É uma comunidade conhecida pela boa água, que era bombeada das dunas por um sistema engenhoso de moinhos de vento feitos de bambu, ainda existentes. Sua sobrevivência hoje se baseia na pesca e na retirada de mariscos do mangue. As disputas econômicas são geradoras de grandes conflitos políticos e diversas pressões sobre a comunidade.

A criação de camarões em cativeiros tem sido fortemente incentivada pelo estado, que traz grandes proprietários para ocupar parte das terras, o que já destruiu grande extensão do mangue. As ocupações capitalistas que procuram desalojar as populações têm hoje novo motivo com a possibilidade da criação de grandes parques de produção de energia eólica. Quanto à população em idade escolar, esta é bastante ampla, sendo parte da escolarização garantida na escola local e parte na cidade.

2. Quilombos de Pacajus: Distantes $50 \mathrm{~km}$ da capital Fortaleza, são comunidades historicamente reconhecidas como negras e marcadamente discriminadas. Os quilombos são denominados Alto Alegre, no lado de Horizonte, e Quilombo da Base, no lado de Pacajús. São grupos vizinhos, cuja população tem um grande grau de parentesco entre si, inclusive com a realização de casamentos dentro da mesma família. As duas comunidades são hoje muito próximas dos centros urbanos e podem ser descritas como bairros da zona rural.

No passado, sua produção era basicamente a castanha de caju e farinha de mandioca. Hoje, parte da população trabalha na cidade e nas fabricas da região. Entretanto, um certo número de atividades permanece ligado à produção de mel, doces, farinha e castanha de caju. A educação é realizada em um conjunto de três escolas e uma creche. Existe uma forte atuação do movimento juvenil negro nessas localidades. 
3. Quilombo da região de Novo Oriente: Minador e Bom Sucesso. Distante $400 \mathrm{~km}$ de Fortaleza, são comunidades de Serra localizadas na divisa entre Ceará e Piauí. Enfrentam os problemas da seca e os rigores do inverno (estação das chuvas), o que torna bastante difícil o acesso à região durante todo o período chuvoso. As atividades econômicas são a plantação de cana e a produção de farinha. As populações exploram muito a caça e a coleta dos produtos da serra como o mel.

O sistema político de autoritarismo agrário é bastante marcante. As escolas estão situadas nas comunidades e cada uma possui apenas uma sala. Parte da população em idade escolar cursa as séries finais na sede do município, enfrentando, entretanto, a inconstância dos transportes, o que se apresenta como um grave problema. Cada uma das comunidades tem em torno de 500 pessoas.

4. Caucaia: Na região metropolitana de Fortaleza, nove comunidades negras localizadas no alto e no pé das Serras reivindicam o status de Quilombo, uma vez que, com o apoio do NACE, foi possível constatar uma presença significativa de patrimônio histórico-cultural de matriz africana nas referidas áreas. Algumas delas hoje já cumpriram a primeira fase de reconhecimento pela Fundação Palmares.

\section{Pret@gogia: a criação de um referencial teórico-metodológico empretecido}

\section{O galo preto}

Exu andava pelo mundo em busca de novidades. Vivia entediando e a falta de criatividade dos seres vivos o deixava profundamente irritado.

- Tudo sempre igual ... pensava com seus botões. - ... Ninguém inventa ou modifica nada. Que tédio! Assim, observou que a noite se aproximava e, junto dela, a ameaça de uma tempestade. Resolveu, então, buscar abrigo numa casa à beira da estrada.

Batendo à porta, foi recebido por um animal peludo ao perguntou:

- Como te chamas?

- Macaco!

- E teu pai, como é chamado?

- Macaco!

- Tua mãe?

- Macaca!

- Teus irmãos?

- Todos, Macacos! 
Exu virou as costas e afastou-se sem dizer mais nada. Não iria passar a noite numa casa onde todos os habitantes tinham o mesmíssimo nome, o que, para ele, representava a mais absoluta prova de falta de imaginação.

E Exu jamais gostou de gente ou animal obtuso.

Logo adiante encontrou outra casa e, batendo à porta, foi recebido por outro animal.

- Boa tarde! Ando em busca de abrigo para proteger-me da tempestade que se aproxima, mas antes preciso saber o teu nome - disse Exu cheio de autoridade.

- Eu me chamo Elefante - respondeu o morador.

- E teu pai? - perguntou o visitante.

- Elefante, como eu!

- Tua mãe?

- Elefante também!

- Teus irmãos?

- São em número de três e chamam-se Elefante, Elefante e Elefante.

- Ora bolas! - resmungou Exu enquanto se afastava sem se despedir.

Mais alguns passos e Exu encontrou outra casa, onde foi recebido por uma pequena ave de plumagem inteiramente negra.

- Olá! Sou Exu e ando em busca de abrigo mas, antes de tudo, preciso saber teu nome.

- Me chamam Galo Preto! - respondeu o morador.

- E tua mulher?

- Galinha.

- Teus filhos?

- Isto depende de suas idades - explicou o dono da casa - Os mais velhos são frangos e frangas, os mais novos são pintos e os menores são chamados pintinhos!

Encantado com a resposta, Exu resolveu pernoitar naquela casa e graças a este fato adquiriu grande admiração pelo galo preto, que, ainda hoje, considera o seu animal favorito (MARTINS, 2005, p. 33).

Dentro da mitologia africana iorubana, Exu é o orixá que ocupa lugar de destaque, porque existe desde a criação do universo e é elo por excelência entre mundo visível e mundo invisível. É ele quem mantém o equilíbrio das trocas, provocando o conflito para promover a síntese. Tudo aquilo que se une, que se multiplica, que se separa e que se transforma é provocado por vontade de Exu. É o regulador do Cosmo, quem põe os demais orixás em contato entre si. Sua função é dinamizar, mobilizar, transformar e 
comunicar. É o passado, presente e futuro. Nele estão contidos o bem e o mal. É a manifestação de tudo o que existe. Exu é guerreiro, afasta o mal do caminho. Cuida da proteção das casas e cidades. Ele funciona de forma positiva quando é bem tratado e, quando desconsiderado, o seu inverso também é verdadeiro.

Exu é também o orixá da comunicação: leva e traz a mensagem de Orunmilá (orixá que se manifesta no jogo de búzios), aquele que Olodumare (o Deus Supremo) permitiu que fosse testemunha da criação de tudo que na Terra existe, portanto o guardião dos segredos, e está presente desde a nossa criação primeira e também a cada vez que aqui retornamos no processo de evolução. Assim, Exu torna possível aos seres humanos, por meio de Orunmilá, tomarem conhecimento ou aproximarem-se dos segredos do passado, presente e futuro. Exu é o orixá que abre caminhos, tem o poder de comunicar, é o mensageiro, por isso está associado aos órgãos da fala.

Tendo consciência de que por meio desse curso de especialização poderíamos abrir caminhos para que professores e professoras de áreas quilombolas pudessem apreender a cultura afro-brasileira é que sentimos, assim como EXU, a necessidade de lidar com uma proposta curricular que fosse inovadora em suas bases conceituais e filosóficas de origem materna, ou seja, baseada nos princípios da cosmovisão da Mãe África. Nesse sentido, o uso de metodologia diferenciada se fez necessário, pois estávamos a tratar das particularidades de expressões dos/as afrodescendentes, o que levaria à intervenção no modo como estão estabelecidas as relações sociais brasileiras. O uso dessa metodologia diferenciada focada em um novo paradigma conceitual para produção de saberes, conceitos e conhecimentos visa, portanto, a "uma autonomia do pensamento do afrodescendente com relação à produção eurocêntrica ocidental” (CUNHA JR., 2007, p. 9).

Nessa perspectiva é que criamos a Pret@gogia - um referencial teórico-metodológico para lidar com a História e Cultura Africanas e Afrobrasileiras, fazendo uso de uma metodologia de ensino e de pesquisa que considera a aprendizagem como uma ação envolvendo corpo e mente, ou seja, uma aprendizagem de corpo inteiro. Daí o entendimento de que a aprendizagem envolve vivências corporais, visitações a alguns espaços-recursos e ainda rodas de conversas com pessoas e grupos detentores de saberes relevantes para os temas estudados. Significa dizer que a produção de saberes efetiva-se por meio do corpo (não existindo a ideia de corpo e mente, mas só corpo) que integra emoção, razão, ludicidade, sensação, intuição e sentimento.

Definimos o currículo escolhendo conteúdos e suas estratégias de ensino-aprendizagem, as formas de avaliar os/as cursistas, os/as formadores/as e as ações da coordenação. Por outro lado, decidimos também quais referenciais metodológicos de pesquisa seriam utilizados pelos/as cursistas. Preocupamo-nos ainda com o cardápio para o corpo físico, de modo 
que, levamos para o curso uma alimentação com a qual os corpos pudessem ser afetados por uma proximidade à cultura afrobrasileira.

Propomos então alimentos livres de frituras, conservantes e evitamos a ingestão de refrigerantes. Estávamos seguindo um dos princípios da cosmovisão africana que é a ideia do corpo como espaço do sagrado e, nesse sentido, cabia pensar o alimento dado ao corpo, ideia que seria trabalhada no módulo Consciência Corporal Africana e Ancestralidade. Acreditamos que essa alimentação traria para nós, equipe de coordenação e cursistas, alguns ensinamentos e, por certo, um deles seria o de não apenas falar sobre uma alimentação saudável, mas senti-la por meio da degustação, do toque, do cheiro e da estética.

Assim, buscamos vivenciar a tradição oral em que

a palavra tem um poder misterioso, pois palavras criam coisas. Isso pelo menos é o que prevalece na maioria das civilizações africanas. Os Dogon sem dúvida expressam esse nominalismo de forma mais evidente; nos rituais constatamos em toda parte que o nome é a coisa, e que 'dizer' é 'fazer' (VANSINA, 2010, p. 140).

\section{Fundamentos da "Pret@gogia”}

Construímos uma estrutura curricular voltada para o ensino e a pesquisa assentados nas experiências e diversas intervenções que já desenvolvíamos aqui no Ceará, a exemplo: a) da professora Sandra Petit com a interligação da cosmovisão africana e a sociopoética na educação e na pesquisa, isso porque “tudo parte do corpo, o corpo é a referência” (CRUZ; PETIT, 2008, p. 05);

b) dos trabalhos desenvolvidos pelo educador físico Norval Cruz (2011) com as vivências propiciadas pela consciência corporal africana;

c) da pedagoga Rebeca Alcântara e Silva (2010) com a elaboração de projeto político-pedagógico enraizado no corpo, uma vez que:

o projeto político pedagógico da escola deve conter a preocupação com o cumprimento da lei ao longo de todo o ano letivo. Sua aplicação deve acontecer em seu cotidiano, nos diferentes níveis e modalidades de ensino (...) (CARNEIRO; SILVA, G.; SILVA, R., 2010, p. 17-18);

d) a abordagem da afrodescendência elaborada por Cunha Jr. (2007), que entrelaça a importância das questões de ordem identitária aos aspectos da ancestralidade e territórios africanos e afrobrasileiros, defendendo a necessidade:

de um novo campo de produção científica especifico das populações de descendência africana, tratando da população desta realidade na sua própria 
ótica é que levou uma incorporação dos conhecimentos histórica da cultura africana e da base do conhecimento denominado de afrodescendência (2007, p. 03-04).

e) Por fim, dos trabalhos da professora Geranilde Costa com a produção didática de literatura oral afro-brasileira, que permite assim “(...) criar, dentro da escola, novos espaços de aprendizagem em que as crianças possam utilizar esse referencial literário para pensar o ser negro” (SILVA, 2009, p. 32).

Logo em seguida, aliamos a essa base conceitual outras referências, tais como:

a) a crítica sócio-antropológica de Kabengele Munanga, pondo em questão a falácia da democracia racial que, segundo ele, é uma “(...) ideologia de mestiçagem, minimizando os impactos das desigualdades raciais e étnicas, o que complica bastante o debate público, o andamento das políticas e a definição de leis” (MUNANGA, 2010, p. 8);

b) a conceituação de arkhé de Muniz Sodré (2005), “que remete às particularidades das culturas fundamentadas na ancestralidade que vivem a indissociabilidade da natureza e da cultura";

c) os ensinamentos da Filosofia da Ancestralidade de Eduardo de Oliveira (2009), quando esse afirma que a Ancestralidade:

(...) é o princípio que organiza o candomblé e arregimenta todos os princípios e valores caros ao povo-de-santo na dinâmica civilizatória africana. (...) a ancestralidade é um princípio regulador das práticas e representações do povo-de-santo. (...) Passa, assim, a configurar-se como uma epistemologia que permite engendrar estruturas sociais capazes de confrontar o modo único de organizar a vida e a produção no mundo contemporâneo (2009, p. 03-04).

d) a abordagem de pesquisa-intervenção, de Piedade Lino Videira (2010):

(...) dialogarmos numa outra perspectiva, e por meio dela criarmos uma nova filosofia dentro da comunidade escolar alicerçada pelo diálogo, aproximação, afetividade, conhecimento sobre a comunidade que se avizinha à escola, planejamento aberto sujeito a mudanças constantes e planejamentos (...) (2010, p. 46).

e) o auto-reconhecer-se afrodescendente: alguém que sabe que faz parte de um tronco/linhagem de origem negra africana. É saber que sua história de vida já foi iniciada por meio dos seus ancestrais. É assumir essa descendência africana com um comportamento positivado, sabendo que "viver sem história é ser uma ruína ou trazer consigo as raízes de outros. É renunciar à possibilidade de ser raiz para outros que vem depois” (KI-ZERBO, 2010, p. 57); 
f) lugar histórico e socialmente atribuído ao ser negro: dar-se conta de que o racismo é algo estrutural em nossa sociedade, determinando o lugar social de negros e brancos. Daí a necessidade de reconhecermo-nos como NEGROS e rechaçarmos a ideia de um país sem racismo, a falácia da democracia racial e a ideia da mestiçagem.

(...) É difícil assumir que a cultura da sociedade brasileira é racista. (...) é inculcado nas crianças em formação um distanciamento de suas raízes africanas, embora façam parte de nosso cotidiano. (...) o racismo continuar a atuar entre as relações humanas, apoiado em outras variáveis, culturais e históricas, e se escondendo (no caso específico do Brasil) nas questões de origem socioeconômicas. (...) Mesmo aceitando "nossa” mestiçagem como querem, devemos saber quem somos, de onde viemos e para onde vamos (MUNANGA, 2010, p. 04).

\section{Princípios da Cosmovisão Africana que subsidiam a Pret@gogia}

A apropriação dos valores mais fortes das culturas de matriz africana, notadamente os de ancestralidade, se reporta aos conhecimentos produzidos por um grupo. Saberes esses que, segundo Sodré (1988, p. 22), dão “identidade a um grupo”, "são as marcas que ele imprime na terra, nas árvores, nos rios”. Saberes que dão vida e significado à história de um grupo e permitem-no diferenciarmo-nos dos demais. Os valores de ancestralidade são enxergados como poder caro aos mais velhos: "seus guardiões são os velhos de cabelos brancos, voz cansada, e memória um pouco obscura, rotulados às vezes de teimosos e meticulosos (veillisse oblige!) ancestrais em potencial...” (KI-ZERBO, 2010, p. 38).

A ancestralidade, segundo Oliveira (2009), deve também ser concebida como

(...) o signo da resistência afro descendente. Protagoniza a construção histórico-cultural do negro no Brasil e gesta, ademais, um novo projeto sócio-político fundamentado nos princípios da inclusão social, no respeito às diferenças, na convivência sustentável do Homem com o MeioAmbiente, no respeito às experiências dos mais velhos, na complementação dos gêneros, na diversidade, na resolução dos conflitos, na vida comunitária entre todos (2009, p. 3).

A tradição oral valoriza o conhecimento que é produzido e repassado por meio da oralidade, seja por meio da fala, dos sons manifestados pelos elementos da natureza (seres humanos e demais seres), dos instrumentos (musicais ou não), que contam e recontam os cortejos de vida de cada povo. Assim, para compreendermos a tradição oral, devemos saber que

Uma sociedade oral reconhece a fala não apenas como um meio de comunicação diária, mas também como um meio de preservação da sabedoria 
dos ancestrais (...) um testemunho transmitido verbalmente de uma geração para outra. (...) a música encontra-se de tal modo integrada à tradição que algumas narrativas somente podem ser transmitidas sob a forma cantada. (...) A oralidade é uma atitude diante da realidade e não a ausência de uma habilidade. (VANSINA, 2010, p. 139-140).

\section{A tradição oral africana encerra seus saberes por meio do mito que}

Faz parte do jeito de educar (...). Os mitos de matriz cultural evidenciam valores de convivência e solidariedade, considerando: saber sobre si mesmo (autoconhecimento); reconhecimento e manutenção de valores de convivência comunitária; reverências aos ancestrais e aos espíritos dos familiares; apreço a figura da mãe, venerado quase como uma entidade; reverência aos mais velhos e velhos, como portadores de conhecimentos; preservação dos fazeres e saberes, costumes e histórias das comunidades; atenção para a educação de crianças e jovens, com os princípios e valores da comunidade; manutenção da família, enquanto instituição básica da sociedade (MACHADO, 2006, p. 04).

O princípio do corpo enquanto fonte espiritual, produtor de saberes, considera o corpo parte do território da natureza e, como tal, elemento de sacralidade: um corpo que, por excelência, comunica-se e produz fazeres e saberes. Um corpo que fala por meio da palavra, do gesto, toque, choro e também por meio da dança, pois:

(...) a dança é um ponto comum entre todos os ritos de iniciação ou de transmissão do saber tradicional. Ela é manifestadamente pedagógica ou 'filosófica', no sentido de que expõe ou comunica um saber ao qual devem estar sensíveis as gerações presentes e futuras. Incitando o corpo a vibrar ao ritmo do cosmos, provocando nele uma abertura para o advento da divindade (o êxtase), a dança enseja uma meditação, que implica ao mesmo tempo corpo e espírito, sobre o ser do grupo e do indivíduo, sobre arquiteturas essenciais da condição humana (SODRÉ, 1988, p. 124).

Um corpo animado pelo som... Um som marcado de significado... Que lhe dá a noção exata da ligação com o mundo real e espiritual:

Pela música, pelo canto e, sobretudo, pela dança, somos arrastados na corrente cósmica do ser e da vida e gozamos de uma espécie de imortalidade. O tempo para. Velhice, decadência e morte se anulam. Entramos no fluxo da juventude e da alegria, do triunfo contra o nada e a insignificância (MOTTA, 1994, p. 4).

A religiosidade permite entender a sacralidade de tudo que dá vida (animais e vegetais) e de tudo aquilo que permite que a vida se estabeleça, se propague, se prolongue (o reino mineral, o sol, a lua). Por meio da religiosidade, compreende-se o valor e a importância de cada ato, cada gesto e cada ser, pois se sabe que tudo, todos os seres vivos e não vivos, 
estão intimamente próximos, entrelaçados, pois atuam em conjunto para que haja o equilíbrio pleno da natureza.

Nessa perspectiva, seres vivos não se sobrepõem aos seres não vivos, seres humanos não se colocam em posição de superioridade frente a outros seres vivos. Dessa compreensão de religiosidade, nasce o princípio da circularidade, em que eu sou por meio do outro. Compreender que tudo que atinge a mim também atinge ao outro. Trata-se, na verdade, de entender que o outro é a minha extensão. Desse modo,

o pensamento africano é holístico. Como tal, ele reconhece a íntima interconectividade e, mais precisamente, a interdependência de tudo. De acordo com o ethos do ubuntu, uma pessoa não só é uma pessoa por meio de outras pessoas (isto é, da comunidade em sentido abrangente: os demais seres humanos assim como os ancestrais), mas uma pessoa é uma pessoa por meio de todos os seres do universo, incluindo a natureza e os seres não humanos. Cuidar “do outro" (e, com isso, de si mesmo), portanto, também implica o cuidado para com a natureza (o meio ambiente) e os seres não humanos (LOUW, 2011).

Temos entendimento da noção de território enquanto espaço-tempo socialmente construído e perpassado da história de várias gerações e formado por uma complexa rede de relações sociais, sendo esse espaço perpassado de sacralidade (PETIT; SILVA, 2011). Assim, o território “(...) apresenta um significado concreto, que vai além do físico e material, envolvendo as formas de relação de uma sociedade com seus ideais e representações, como também traduz o comportamento de indivíduos e os sentimentos coletivos de vinculação a uma organização social” (RÊGO, 2010, p. 44).

\section{Da concretização da Pret@gogia: metodologia de encontro com seu “Eu negr@”}

Montamos cinco (05) módulos de estudo, os quais tinham uma média de quatro (04) temas estudados, cada um. Eis as etapas:

a) ETAPA 01 - Conceitos e Realidades do Quilombo;

b) ETAPA 02 - Corpo, Ancestralidade e Religiosidade Afro-Brasileira;

c) ETAPA 03 - História da África e dos Movimentos Sociais Negros no Brasil;

d) ETAPA 04 - Práticas pedagógicas, africanidades e manifestações culturais;

e) ETAPA 05 - Metodologias de pesquisa e ensino

Como critério para a escolha dos temas das etapas selecionamos conteúdos que julgamos necessários para que os/as cursistas pudessem 
desnaturalizar a falácia da igualdade racial e, de outro, ter acesso a uma literatura afro-brasileira que viesse a desconstruir informações preconceituosas e equivocadas que versavam sobre a África e sobre a cultura afro-brasileira. Daí passamos a fazer uso, dentre outros, de obras da Literatura Afrodescendente, sendo que:

O conceito de literatura negra não se atrela nem à cor da pele do autor nem apenas à temática por ele utilizada, mas emerge da própria evidência textual cuja consistência é dada pelo surgimento de um eu enunciador que se quer negro. (...) [um] eu lírico em busca de uma individualidade negra instaura um novo discurso - uma semântica do protesto - ao inverter um esquema onde ele era o Outro: aquele de quem se condoíam ou a quem criticavam (BERND apud PEREIRA, 2007, p. 187).

Nessa perspectiva, Eduardo de Assis Duarte declara que a:

[a] conformação teórica da literatura "afro-brasileira” ou "afro-descendente” passa, necessariamente, pelo abalo da noção de uma identidade nacional uma e coesa. E, também, pela descrença na infalibilidade dos critérios de consagração crítica presente nos manuais que nos guiam pela história das letras aqui produzidas (DUARTE apud PEREIRA, 2007, p. 187).

Também apresentamos a Sociopoética e Pesquisa-intervenção como referências teórico-metodológicas de pesquisa a serem utilizadas para a construção das monografias.

A Sociopoética é um método de pesquisa e aprendizagem e defende que:

pesquisar com o corpo todo significa desencadear as potências criadoras das pessoas e descobrir o imaginário muitas vezes esterilizado pela rotina massacrante do cotidiano. A liberação das capacidades artísticas adormecidas é geralmente vivido pelo grupo [...] como um fluxo de auto-liberação muito importante, ao descobrir ou reativar suas potencialidades abafadas no dia a dia (PETIT, 2002, p. 17)

Esse referencial vem propor uma outra forma de fazer pesquisa em que não haja:

o corte da cabeça do resto do corpo, da emoção, da intuição e da sexualidade; [...] a consideração dos não especialistas como incapazes de participarem da produção do conhecimento; a separação entre aprendizagem científica e desenvolvimento artístico; a separação entre o conhecimento e a espiritualidade (GAUTHIER apud PETIT; SOARES, 2001).

Dessa forma, influenciados pela Sociopoética e pelos princípios da cosmovisão africana julgamos conveniente iniciarmos todos os módulos com dança. Assim, os corpos eram convidados a distanciarem-se das cadeiras e dos calçados, de modo que cursistas e coordenação tinham o 
chão como assento do corpo... sentido-o e tocando-o, mas também sendo tocados por esse. Essa postura também favoreceu aos nossos corpos estarem mais próximos e tocarem uns aos outros com frequência, o que resultou em constantes expressões de carinho mútuo entre todos e todas.

Dessa forma ritualística, convidávamos nossos ancestrais a estarem conosco e a abençoarem a nossa estadia naquele espaço quilombola. A dança foi particularmente valorizada porque é uma expressão da tradição oral africana e que, segundo Videira (2010) (ao sentido espiritual da dança no quilombo que estudou):

[...] a dança não é espetáculo, não dançam para se exibir dentro de seus festejos. Dançam para celebrar seus ancestrais e os conhecimentos que eles plantaram dentro de cada um(uma). Dançam porque se re-ligam com seus antepassados. E esticam o tecido dessa história para envolver seus descendentes. Dançam porque para festejar tem de dançar. Dançam porque seus(as) santos(as) vêm dançar junto consigo (2010, p. 56).

Também encerrávamos os módulos com dança e, assim, mantínhamos esse sentido espiritual. Logo no primeiro módulo a professora Piedade Videira elegeu como símbolo do curso uma cabaça e assim se instituiu o momento de Entrega da Cabaça do grupo, espaço em que o/a beneficiado/a por esse artefato preparava uma dinâmica ou vivência para realizar a passagem à pessoa escolhida para ser o/a novo/a detentor/a da cabaça. Esse era um momento de fortes simbologias e ritualização de oferenda da energia vitalizada da cabaça, entendida como fortalecimento dos laços comunitários e empoderamento da pessoa escolhida a ser guardiã pela responsabilidade outorgada em nome do grupo como um todo.

Incentivamos que o grupo de cursistas fizesse uso de linguagens variadas, sem que para isso tivessem que abdicar da escrita, porém buscassem utilizá-la com leveza e criatividade e, sobretudo, pela via de uma escrita personificada, marcada pelo EU, em vez do NÓS, como preveem algumas correntes teóricas. Para tanto, solicitamos que os/as cursistas produzissem um Memorial de suas vidas, sendo que primeiro construiriam Árvores de Saber (produção em forma de árvore) em que registravam, para cada faixa etária de sete anos, sete saberes adquiridos sobre o Ser Negro/Negra. Posteriormente, cada cursista escolhia um tipo de escrita para relatar seus saberes negros, por exemplo: cordel, carta, texto etc. A partir dessa atividade percebemos que existia um verdadeiro apagamento das memórias negras dos cursistas, o que nos levou a todo um exercício para que esses saberes fossem recobrados. Logo abaixo expomos alguns trechos desses memoriais:

$1^{\circ}$ - Lembranças das informações obtidas na escola sobre o Negro:

Como todas as crianças, aprendi nas minhas primeiras aulas de História do Brasil, que o povo negro era um povo feito para o trabalho pesado e que 
por isso vieram de seu país para as nossas lavouras de cana-de-açúcar. Só depois é que tomei conhecimento que eles eram arrancados de suas terras, trazidos nos imundos porões dos navios, onde ficavam acorrentados e amontoados, passando meses sem ver a luz do sol, recebendo uma péssima alimentação, sem higiene, vítimas de doenças e que muitos chegavam a morrer devido a toda essa situação desumana (Naza, cursista)

$2^{\circ}$ - Escrita de uma paródia apresentando experiências de vida marcadas pelo racismo:

Ai que saudade D’Oce - Geraldo Azevedo

Desde criança acostumada

por ser negra a minha cor

era chamada de negrinha

ou "negrinha do pajeú”

Minhas bonecas eram bruxinhas

Brinquedos de pano e de cor

Na escola, por ser moreninha

Os meninos não davam valor

Na escola vi o sofrimento

Que a História por tempos guardou

De um povo que foi humilhado

Julgado pela sua cor

Trazia no peito a vontade

Apenas de se libertar

E de ter mais dignidade

O seu espaço conquistar

O tempo passou, fui crescendo

Então é que pude notar

O espaço do negro crescendo

Sua contribuição aumentar

Amigos na universidade

$\mathrm{E}$ até líderes mundiais

Destaques na sociedade

Luta por direitos iguais

Para aprender sobre o assunto

Atuei em peças teatrais

A cultura afro cearense

Aprendi com histórias reais 
Distritos de antigos quilombos

Histórias, festa e tradições

Conhecimento importante

Dos negros, contribuições

Agora com curiosidade

Um curso resolvi fazer

Conhecer descendentes de escravos

E antigos quilombos pra ver

Cultura e religiosidade

Crenças e costumes antigos

Respeito à ancestralidade

Saberes a nós concedidos.

Mesmo aprendendo bastante

Tem mais que preciso saber

A história de minha descendência

E mais religiões aprender

Sobre o continente africano

Assuntos para debater

Conscientizar as pessoas

Da importância do negro ver

Ancestralidade africana

A “sankofa” e a cosmovisão

As comidas africanas

E assuntos da religião

Saberes adquiridos

Ao longo do curso exercido

Levarei sempre comigo

aos negros, a gratidão

Quero agradecer a NACE

Pela contribuição

Pela experiência vivida

Com grande satisfação

Terás papel importante

Pra minha cosmovisão

Contribuindo bastante

Para minha formação. 
$3^{a}$ - Produção de uma carta relatando experiências de práticas racistas:

Amigo, você deve se lembrar muito bem que na época em que nós fazíamos a alfabetização. Todos diziam que "todo negro é ladrão", "negro só serve para arrancar toco". Quando a Germana chegava com aquele jeito sapeca, nós dizíamos: “Chegou a negra do Pajeú!”. Palavra pejorativa, que era a marca de um óleo comestível. Lembra do nosso "colega de cor”, como todos chamavam? Pois sim, quando desaparecia um objeto qualquer na sala de aula, todos diziam ser ele o ladrão. Era um dos negros da sala. Esse mesmo colega tinha muita dificuldade de assimilar as matérias e todos chamavam de burro. (...) Lembro-me o que dizia o Sr. Antonio, "negro só serve para arrancar toco e encher a paciência do patrão”. Imagine, meu querido amigo, como era há cinquenta anos. O nosso grande amigo Jacó, subnutrido, não assimilava praticamente nada da matéria na escola. Era taxado por todos nós de "jumento". Não gosto nem de lembrar, pois tenho raiva de mim mesmo. (...) As férias eram o período mais esperado do ano. A cena era a mesma, todos nós íamos para o sítio do Sr. Antonio. Passávamos o dia brincando, pescando, apostando corrida a pé, andando a cavalo. $\mathrm{O}$ almoço era servido na mesa das varandas, pois éramos rapazinhos. Ao terminar, corríamos para o açude e os amigos negros ficavam retirando os pratos e passando o pano no chão. Dizíamos não ter preconceito, mas, por coincidência, sempre ficavam no "batente" os nossos amigos de cor. Lembra do que o Júlio nos disse e até chorou? Gostava muito de todos nós, mas tinha muita vontade de morrer, porque sabia que por mais esforço que fizesse para subir na vida, não conseguiria, unicamente por causa da cor. Aquilo me chocou muito, mas logo depois passou despercebido. Hoje, consigo perceber melhor o drama vivido por Júlio e isso me dá uma angústia danada (...). O curso de Africanidades está passando a limpo os meus preconceitos e a história do Brasil e do mundo. O que nos aprendemos nas escolas é que o continente africano era horrível. Era como se fosse o retrato do inferno. Os negros não eram iguais aos brancos, estavam mais para animais, precisamente os macacos. Os navios negreiros traziam estes animais para servir os brancos. Eram desobedientes e tinham de ser tratados na chibata. Tudo isso nos foi passado na escola, você deve se lembrar muito bem. Quanta maldade, quanta ignorância e quanto preconceito! Lembranças, lembranças, que jamais serão esquecidas. Gravadas em nossas consciências. Muitas vezes erramos, não por maldade, mas por ignorância, por falta de conhecimento, por conceitos errados. Meu amigo, graças a Deus que ainda temos tempo de reconhecer e pedir perdão pelos nossos erros.

Percebemos pelas reações ao longo do Curso e principalmente por ocasião das defesas de monografias, que a principal reviravolta promovida pelo Curso foi a auto-afirmação como negra e negro, pois foi quase unânime essa identificação na apresentação dos trabalhos finais. Isso aconteceu espontaneamente nas defesas, sem que nenhum de nós sugerisse, mas foi sem dúvida efeito do memorial e das vivências propiciadas. Ora no início do Curso essa identificação era na maioria dos casos ausente ou tímida e hesitante. Atribuímos essa mudança primeira à metodologia que 
empregamos, ou seja, à Pret@gogia, que favorecia a vivência dos princípios da cosmovisão africana no corpo. Acreditamos que se jamais tocaríamos o íntimo das pessoas apenas pela via racional da leitura e escrita formal. Daí que foi indispensável colocar o corpo em estado de movimentação, desterritorialização e desconstrução. Só assim foi possível quebrar os blocos de desvalorização e apagamento da negritude erguidos pela nossa História afro-diaspórica no corpo de cada um e cada uma.

Outro aspecto fundamental foi o trabalho sobre a dimensão autobiográfica, fortalecida por um espaço-tempo favorável, uma vez que esse processo necessitou de muitas idas e vindas na memória de cada um/a. $\mathrm{O}$ fato de termos mais de dez meses de convivência intensa em finais de semana quinzenais e ainda um período de sete meses para elaboração da monografia ajudou na maturação lenta da auto-identificação.

Esse resultado é apenas um dos tantos que percebemos, mas que destacamos aqui, pois acreditamos que tenha sido fundamental para gerar nos cursistas o desejo de fazer diferença, fazendo diferente, sobretudo, independentemente de sua cor de pele, fazer de modo empretecido, fazer pret@gogia.

\section{Referências}

CARNEIRO, Isabel; SILVA, Geranilde; SILVA; Rebeca (Org.). Atualizações da Lei de Diretrizes e Bases da Educação Nacional. Fortaleza: UAB/IFCE, 2010.

CRUZ, Norval; PETIT, Sandra. Arkhé, corpo, simbologia e ancestralidade. In: $31^{\circ}$ ENCONTRO ANUAL DAANPED, 2008. Anais... Caxambu, 2008.

CRUZ, Norval. Consciência Corporal e Ancestralidade Africana. $1^{\mathrm{a}}$. ed. Fortaleza: Fundação Demócrito Rocha, 2011.

CUNHA JR., Henrique. Metodologia Afrodescendente de Pesquisa. Texto mimeografado para estudos na disciplina Etnia, gênero e educação na perspectiva dos Afrodescendente. Faculdade de Educação, UFC, 2007.

GAUTHIER, Jacques. Sociopoética. Encontro entre arte, ciência e democracia na pesquisa em ciências humanas e sociais, enfermagem e educação. In: PETIT, Sandra H.; SILVA, Rosileide de Maria(Org.).Algumas contribuições da sociopoética à construção coletiva do conhecimento na pesquisa em educação popular. In: 25 ENCONTRO DA ANPED, 2001. Anais... Caxambu, 2001.

KI-ZERBO, Joseph. História geral da África. Metodologia e préhistória da África. 2 ed. Brasília: UNESCO, 2010.

LOUW, Dirk. Ser por meio dos outros: o ubuntu como cuidado e partilha. In: Revista UHU Online. n. 35, dez. 2010. Disponível em: http://www. 
ihuonline.unisinos.br/index.php?option=com_content\&view=article\&id= 3687\&secao=35. Acesso em: 15 abr. 2011.

MACHADO, Vanda. Mitos Afro-brasileiros e vivências educacionais. In: Secretaria Municipal de Educação e Cultura (Org.). Pasta de Textos da Professora e do professor. Salvador: SMEC, 2006, v. 01, p. 01-12. Disponível em: http:/www.educacao.salvador.ba.gov.br/documentos/ mitos.pdf. Acesso em: 1 out. 2011.

MARTINS, Adilson. Lendas de Exu. Rio de Janeiro: Pallas, 2005.

MOTTA, Roberto M. Cortez. A Tradição Afro-Brasileira e Sua Expansão em Pernambuco. In: Ciclo de Palestras do NERP/Núcleo de Estudos e Pesquisas em Religiões Populares - Mestrado em Antropologia/ UFPE. Recife, 1994, Mimeo.

MUNANGA, Kabengele. Lutas contínuas concretizam mudanças sociais e raciais. In: RIBEIRO, M. (Org.). Direitos Humanos da Coleção 2003/2010 - “O Brasil em Transformação”. São Paulo: Fundação Perseu Abramo, 2010. Disponível em: http://www2.fpa.org.br/sites/default/files/ Kabengele_Munanga.pdf. Acesso em 03 dez. 2010.

OLIVEIRA, Eduardo de. Epistemologia da Ancestralidade. In: http:// www.entrelugares.ufc.br/entrelugares2/index.html. Acesso set de 2009.

PEREIRA, Edimilson de Almeida. Malungos na escola. Questões sobre culturas Afrodescendentes e educação. São Paulo: Paulinas, 2007.

PETIT, Sandra H. Sociopoética: potencializando a dimensão poiética da pesquisa. Fortaleza: UFC, 2002. Mimeo.

PETIT, Sandra; SILVA, Geranilde. Pret@gogia: referencial teóricometodológico para o ensino da História e Cultura Africana e dos Afrodescendentes. Fortaleza: UFC, 2011.

RÊGO, Jussara. Territórios do Candomblé: a desterritorialização dos terreiros na Região Metropolitanos de Salvador, Bahia. In: www. portalseer.ufba.br/index.php/geotextos/article/download/3038/2186. Acesso em 03 nov. 2010.

SILVA, Geranilde Costa e. O uso da literatura de base africana e afro-descendente junto a crianças das escolas públicas de Fortaleza: construindo novos caminhos para repensar o ser negro. 2009, $127 \mathrm{f}$. Dissertação (Mestrado em Educação Brasileira). Faculdade de Educação Universidade Federal do Ceará, Fortaleza, 2009.

SODRÉ, Muniz. O terreiro e a cidade - a forma social negro-brasileira. Petrópolis, RJ: Vozes, 1988.

SODRÉ, Muniz. Entrevista. Muniz Sodré, intelectual. 2005. Disponível em: <http://www.tribunademinas.com.br/cultura/entrevista-muniz-sodreintelectual-1.1145997>. Acesso em: 10 out. 2012. 
VANSINA, J. Tradição Oral e sua Metodologia. In: KI-ZERBO, Joseph (Ed.) História Geral da África, I: Metodologia e Pré-História da África. 2 ed. Brasília: UNESCO, 2010.

VIDEIRA, Piedade Lino. Batuques, folias e ladainhas: a cultura do Quilombo da Cria-u em Macapá e sua Educação. 2010, 262f. Tese (Doutorado em Educação Brasileira). Faculdade de Educação Universidade Federal do Ceará, Fortaleza, 2010.

Data de submissão: 20/03/2013

Data de aprovação: 12/07/2013 